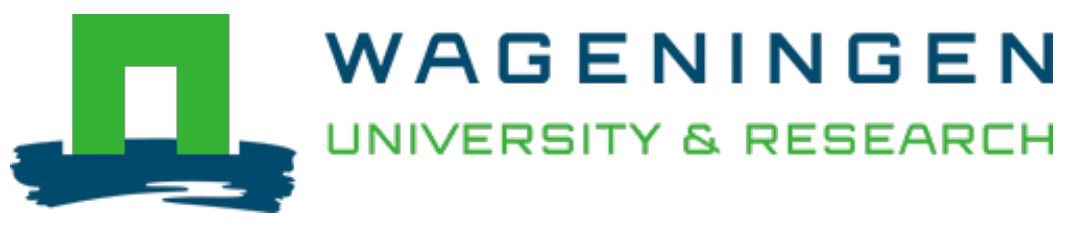

\title{
A bittersweet meal: The impact of sugar solutions and honeydew on the fitness of two predatory gall midges
}

\section{Biological Control}

Fratoni, Stefano; Duarte, Marcus V.A.; Vangansbeke, Dominiek; Wäckers, Felix L.; Dicke, Marcel et al https://doi.org/10.1016/j.biocontrol.2019.104098

This article is made publicly available in the institutional repository of Wageningen University and Research, under the terms of article $25 \mathrm{fa}$ of the Dutch Copyright Act, also known as the Amendment Taverne. This has been done with explicit consent by the author.

Article 25 fa states that the author of a short scientific work funded either wholly or partially by Dutch public funds is entitled to make that work publicly available for no consideration following a reasonable period of time after the work was first published, provided that clear reference is made to the source of the first publication of the work.

This publication is distributed under The Association of Universities in the Netherlands (VSNU) 'Article $25 \mathrm{fa}$ implementation' project. In this project research outputs of researchers employed by Dutch Universities that comply with the legal requirements of Article $25 \mathrm{fa}$ of the Dutch Copyright Act are distributed online and free of cost or other barriers in institutional repositories. Research outputs are distributed six months after their first online publication in the original published version and with proper attribution to the source of the original publication.

You are permitted to download and use the publication for personal purposes. All rights remain with the author(s) and / or copyright owner(s) of this work. Any use of the publication or parts of it other than authorised under article $25 \mathrm{fa}$ of the Dutch Copyright act is prohibited. Wageningen University \& Research and the author(s) of this publication shall not be held responsible or liable for any damages resulting from your (re)use of this publication.

For questions regarding the public availability of this article please contact openscience.library@,wur.nl 


\title{
A bittersweet meal: The impact of sugar solutions and honeydew on the fitness of two predatory gall midges
}

\author{
Stefano Fratoni ${ }^{\mathrm{a}}$, Marcus V.A. Duarte ${ }^{\mathrm{b}}$, Dominiek Vangansbeke ${ }^{\mathrm{b}}$, Felix L. Wäckers ${ }^{\mathrm{b}}$, \\ Marcel Dicke ${ }^{\mathrm{a}}$, Apostolos Pekas, ${ }^{\mathrm{b}, *}$ \\ ${ }^{a}$ Laboratory of Entomology, Wageningen University, Wageningen, The Netherlands \\ ${ }^{\mathrm{b}} R \& D$ Department, Biobest Group N.V., Westerlo, Belgium
}

\section{A B S T R A C T}

Adult survival and reproduction of many species of arthropod natural enemies depend exclusively on sugar-rich food such as honeydew. Here, we tested the impact of two types of honeydew as well as several sugars at different concentrations $(10 \%, 25 \%, 50 \%)$ on the longevity and reproduction of two life-history omnivores. On the one hand, the aphid-feeding gall midge Aphidoletes aphidimyza (Rondani) and on the other hand the gall midge Feltiella acarisuga (Vallot) (Diptera: Cecidomiydae), a predator that can feed on many spider-mite species during the juvenile stage. Compared to a water control, females provided with the commercial sugar Biogluc ${ }^{\circledast}$ at a $10 \%$ concentration showed an increase in longevity by a factor of 3.6 for A. aphidimyza and 4.7 for $F$. acarisuga, respectively, whereas Biogluc ${ }^{\circledR}$ at a $50 \%$ concentration significantly reduced longevity in both species. Sucrose solutions had a positive, yet less pronounced effect. Feeding on Biogluc ${ }^{\circledR}$ or sucrose (all concentrations) raised the number of oocytes for A. aphidimyza and F. acarisuga by a factor $2.2-2.6$ and $2.0-2.5$, respectively. The highest realized fecundity during $72 \mathrm{~h}$ was recorded for $A$. aphidimiza females supplied with $50 \%$ Biogluc ${ }^{\circledast}$ (increase by 5.1) or in the case of $F$. acarisuga the strongest effect was observed with $10 \%$ Biogluc ${ }^{\circledR}$ (increase by 3.5 ). For the rest of the Biogluc ${ }^{\circledast}$ and sucrose solutions the effects were less pronounced. In contrast, aphid honeydew did not raise female longevity, nor the number of oocytes or eggs laid. Our results imply that sugar solutions at modest concentration (10\%) are best suited for use to support these gall midges in the field as well as in mass rearing. Finally, given the positive association between the number of oocytes and the number of eggs laid for both species, we propose the use of the former as a proxy to assess the fertility for both species to simplify the procedures for quality assessments currently employed by the biocontrol industry.

\section{Introduction}

Biological control programs make use of carnivorous insects, namely predators and parasitoids, as well as predatory mites. In augmentative biological control $(\mathrm{ABC})$ the predators and parasitoids are mass-produced to be released in the crop. ABC using arthropods against arthropods, is a sustainable, efficient and increasingly adopted method for pest management in agriculture, either alone or as part of Integrated Pest Management (IPM) (van Lenteren et al., 2017). Many carnivorous arthropod species used in $\mathrm{ABC}$ are true omnivores, as in addition to the pest/prey they also consume food of plant origin at least during part of their lifetime. The main types of plant-provided foods include floral and extrafloral nectar, pollen, food bodies and plant sap. In addition, honeydew, excreted by Sternorrhynchae Hemiptera is also plant derived and its composition reflects the composition of the plant sap (Wäckers et al., 2005). Although the nutritional composition of these food types differs considerably, nectar and honeydew are essentially a source of carbohydrates while pollen is mainly a protein-rich food source. Depending on the developmental stages that use plant-provided food, carnivorous arthropods are classified as permanent omnivores (both juveniles and adults feed on plant-derived food), temporal omnivores (where plant food is used only during part of the life cycle) and lifehistory omnivores (switch from a carnivorous life-style in the larval instar to exclusively feeding upon plant-provided food as adults).

Several fitness components of carnivorous arthropods that are used in ABC, such as longevity (Winkler et al., 2006), fecundity (Tena et al., 2013b) and searching capacity (Takasu and Lewis, 1995), can be seriously compromised in the absence of plant-provided food, especially carbohydrates. Hence, the type, availability and accessibility of the plant-provided food may have a profound impact on the effectiveness of biological control. Interestingly, the attribute of the carnivorous arthropods to exploit plant-derived food has found application in pest management. Food supplements can be provided after the release of the natural enemies into the crop to support their population development in order to establish them preventatively in the crop, i.e. before the arrival of the pest. This strategy is applied in greenhouse crops mainly using pollen of the narrow-leaved cattail Typha angustifolia L. to support populations of omnivorous predatory mites from the family Phytoseiidae (Duarte et al., 2015; Vangansbeke et al., 2016a,b). Another possibility, not yet applied at the growers' level, involves the use of

\footnotetext{
* Corresponding author at: Biobest Group N.V., Ilse Velden 18, 2260 Westerlo, Belgium.

E-mail address: tolis@biobest.be (A. Pekas).
} 
sugar sprays to support predatory insects and mites as well as parasitoids (Beltrà et al., 2017; Tena et al., 2015) or the combination of pollen and sugars (Pekas and Wäckers, 2017).

In the present study, we sought to determine the impact of feeding upon different sugar types and honeydew on several fitness components of two life-history omnivores that are used extensively in ABC, namely the commercially available gall midges Aphidoletes aphidimyza (Rondani) and Feltiella acarisuga (Vallot) (Diptera: Cecidomiydae). The larvae of A. aphidimyza are predators of over 85 aphid species including the economically most important aphid crop pests (see review by Boulanger et al., 2018). The predatory larvae of $A$. aphidimyza switch to an exclusive plant-derived food as adults, such as honeydew and floral nectar for maintenance, reproduction and locomotion (Aparicio et al., 2018; Boulanger et al., 2018). Feeding on natural (Sell and Kuo-Sell, 1987) or synthetic honeydew or sugar solutions at a concentration of $10 \%$ (Watanabe et al., 2014) significantly increased the longevity and fecundity of adult $A$. aphidimyza. Feltiella acarisuga larvae are generalist predators of several spider mite species (Chazeau, 1985). Adults of $F$. acarisuga feed on nectar and honeydew as adults. Interestingly, despite the fact that the prey of $F$. acarisuga do not produce honeydew, Brødsgaard et al., (1999) showed that, feeding on fresh aphid honeydew excreted by Myzus persicae Sultzer (Hemiptera: Aphididae) on cucumber plants, resulted in 2.4 times increased fecundity in comparison to a water control. In fact, the same authors argued that honeydew should be provided to adults of $F$. acarisuga in order to enhance their biocontrol efficacy.

Despite the information available, it is unknown what the impact of different sugar concentrations or fresh honeydew from different aphid species is on the fitness of A. aphidimyza and F. acarisuga. Moreover, identifying sugar sources of known and stable composition that are commercially available would be a useful (as compared to the honeydew provisioning) tool for application both in a mass rearing and in the field following the releases of A. aphidimyza and $F$. acarisuga. Thus, the specific objectives of this study were to test the impact of several honeydews and commercially available sugars on 1) the longevity 2) number of oocytes and 3) fecundity of A. aphidimyza and F. acarisuga. This information will provide useful insights into the nutritional ecology of $A$. aphidimyza and $F$. acarisuga, and may be employed for improving the efficiency of the mass-rearing and biocontrol potential of both species in applied pest control programs.

\section{Material and methods}

\subsection{Insects}

Aphidoletes aphidimyza and $F$. acarisuga were obtained as pupae from the commercial rearing of Biobest Group N.V. (Westerlo, Belgium). For the collection of adults, pupae for both species were distributed equally over six black plastic bottles $(125 \mathrm{ml})$ with a transparent cylindrical tube adjusted on the top (diameter $2 \mathrm{~cm}$ and length $7 \mathrm{~cm}$ ). The containers were stored in a climate chamber at $25^{\circ} \mathrm{C}$ and $70 \%$ relative humidity $(\mathrm{RH})$ and a photoperiod of $16 \mathrm{~L}$ : $8 \mathrm{D}$. Upon emergence $(\sim 2$ days later), mixed sex groups of 20-25 adults were moved to separate tubes and fed with the corresponding diet (for details see below) before being used in the experiments.

\subsection{Sugar solutions and honeydew}

The following sugar solutions and honeydew types were tested: sucrose solution ( $\mathrm{w} / \mathrm{v}$ in water) at concentrations of $10 \%, 25 \%$, and $50 \%$; Biogluc ${ }^{\circledR}$ (see later) at ( $\mathrm{v} / \mathrm{v}$ in water) $10 \%, 25 \%, 50 \%$; fresh honeydew of the pea aphid Acyrthosiphon pisum Harris (Hemiptera: Aphididae) reared on Vicia faba L. variety Boxer and of the green peach aphid M. persicae reared on sweet pepper, Capsicum annuum L. variety Esterel. Based on the initial results, an additional treatment of Biogluc ${ }^{\circledR}$ solution $50 \%+$ separate water source was tested as well in the longevity experiments.

Biogluc $^{\circledast}$ is a ready-to-use sugar solution containing fructose (37.5\%), glucose $(34.5 \%)$, sucrose $(25 \%)$, maltose $(2 \%)$ and oligosaccharides (1\%), and as preservatives potassium sorbate (E202) $0.15 \%$ and citric acid (E330) 0.06\% (Wäckers et al., 2017).

The different sugar treatments were offered to the adults by soaking a cotton ring $(2 \mathrm{~cm}$ external and $1 \mathrm{~cm}$ internal diameter) into a $100 \mathrm{ml}$ plastic falcon tube containing the sugar solution. The cotton disc was then fitted into the internal part of the round lid that was sealing the cylindrical tube (see below). The control treatment consisted of cotton rings dipped in water. Fresh honeydew was collected daily (in the morning) by placing a parafilm piece $(2 \mathrm{~cm}$ length $\times 5 \mathrm{~cm}$ width) under the aphid colonies. Afterwards, it was offered to the adult insects by introducing a piece of the parafilm in the cylindrical tube or into the arena. To prevent the honeydew from crystalizing, $200 \mu \mathrm{L}$ of water was provided on the cotton ring to increase the relative humidity in the experimental tube. New material for all sugar types (including honeydew) and water was replaced daily (the old material was removed).

\subsection{Impact of sugars and honeydew on the longevity of A. aphidimyza and F. acarisuga}

Recently emerged $(<10 \mathrm{~h}$ ) adult females were placed individually in a transparent cylindrical tube (diameter $2 \mathrm{~cm}$ and length $7 \mathrm{~cm}$ ) containing the diet and closed at the top with a perforated lid. Each tube was labelled indicating the treatment as well as the identification number of the individual insect. The tubes were fixed on a perforated cardboard paper that in turn was placed into a plastic container $(30 \mathrm{~cm}$ length $\times 20 \mathrm{~cm}$ width $\times 10 \mathrm{~cm}$ height). Water was added into the plastic container to form a layer of approximately $2 \mathrm{~cm}$ and afterwards $\mathrm{NaCl}$ was added to ensure humidity level of ca. 75\% (Winston and Bates, 1960). Another container of the same size was placed at the top to close the system and maintain a constant humidity. Survival of each individual was assessed daily at 09:00 am. The experiments for A. aphidimyza were conducted from 9 July until 14 August 2018 in eight blocks with each block containing three to six treatments. The experiments for F. acarisuga started on the 2nd of August 2018 including 20 repetitions for each treatment.

\subsection{Impact of sugars and honeydew on the number of oocytes of A. aphidimyza and F. acarisuga females}

Recently emerged $(<10 \mathrm{~h}$ ) adult females were kept individually in a transparent cylindrical tube closed with a lid containing a given diet for $48 \mathrm{~h}$. For dissection, females were placed at $-4{ }^{\circ} \mathrm{C}$ for $1 \mathrm{~min}$, and afterwards, by using an entomological needle, the abdomen was incised and the two ovaries containing follicles (oocytes) were extracted by pulling out the tracheal filament connected to it. The number of mature oocytes was counted using a dissecting microscope at x10 magnification. Mature oocytes were distinguished from mid-vitellogenic oocytes based on coloration. Mature oocytes of A. aphidimyza are fully yelloworange in contrast to early or mid-vitellogenic oocytes, which are white or partially yellow. Mature oocytes of $F$. acarisuga are white with a darker spot on one side. For $A$. aphidimyza, experiments were conducted from 12 July until 6 August 2018 in five blocks in time with each block containing 4 to 6 treatments. For $F$. acarisuga, experiments were conducted from 2 until 6 August 2018 in two blocks in time with each block containing all nine treatments.

\subsection{Impact of sugars and honeydew on the fecundity of A. aphidimyza and F. acarisuga}

For both species we followed the guidelines employed by the biocontrol industry to assess the quality of mass-reared A. aphidimyza (van Lenteren et al., 2003). Newly emerged male and female adults of $A$. aphidimyza or $F$. acarisuga were kept during $24 \mathrm{~h}$ in groups of 
approximately 20 individuals into a cylindrical tube to ensure mating. During this period, they were provided a given feeding treatment. Afterwards, individual females were transferred into the experimental arena consisting of a cylindrical plastic container $(3.5 \mathrm{~cm}$ diameter, $1 \mathrm{~cm}$ height) containing a layer of $2 \mathrm{~cm}$ of $10 \%$ agar. A leaf disc (diameter $3 \mathrm{~cm}$ ) of either $C$. annuum, or $V$. faba was placed on the agar for the experiments with $A$. aphidimyza and $F$. acarisuga. To assess the fecundity of $A$. aphidimyza, a small colony (mixed instars) of 10 adult female $M$. persicae or $A$. pisum was added to the arena using a fine hairbrush. For F. acarisuga, 30-35 individuals of T. urticae (mixed instars) were introduced on a leaf disk of Cucumis sativum L. var Esterell. The sugar sources and water control were supplied to the adult females on a piece of filter paper (VWR European, size: $90 \mathrm{~mm}$, Cat. No. 5160814). The honeydew was supplied on a piece of parafilm. At $72 \mathrm{~h}$ after introduction into the arena, the number of eggs laid was counted for those females that were still alive. Females that had died were discarded from the analyses. For A. aphidimyza, experiments were done on four dates (blocks) from 25 July until 9 August 2018 with each block containing four to six treatments. For $F$. acarisuga, experiments were conducted in two blocks on the 1st and 9 August 2018 with each block containing all nine treatments.

\subsection{Statistical analyses}

We used generalized linear modelling (GLM) techniques assuming Poisson error variance to construct models using the number of days alive, number of oocytes or number of eggs laid as dependent variables and treatment, date (=block) and their interaction as the main factors. Non-significant main factors and interactions were dropped from the model at a significance level of 0.05 . When an over- or under-dispersion was detected, we re-evaluated the significance of the explanatory variables using an F-test after rescaling the statistical model by a Pearson's chi-square divided by the residual degrees of freedom (Crawley, 2007). Moreover, LSD post hoc tests were performed using the function glht from the MULTCOMP package for R. Finally, we use linear regression to explore the association between the number of oocytes and the number of eggs laid (in both cases we used the average for each treatment). All data analyses were performed with the $\mathrm{R}$ freeware statistical package (http://www.R-project.org/).

\section{Results}

\subsection{Impact of sugars and honeydew on the longevity of A. aphidimyza and F. acarisuga}

Treatment had a significant effect on the longevity of adult $A$. aphidimyza females $(F=41.283$, d.f. $=9,275 ; P<0.0001)$ (Fig. $1 \mathrm{~A}$ ) whereas block $(F=1.64$; d.f. $=1,274 ; P=0.246)$ and the interaction block*treatment $(F=1.567$; d.f. $=9,265 ; P=0.238)$ were not significant. Females lived longest when provided with Biogluc ${ }^{\circledR} 10 \%$. When compared to the water control, feeding on Biogluc ${ }^{\circledast}$ enhanced longevity by a factor of 3.6. The sucrose solutions had a less pronounced effect on female longevity (increase by a factor of 1.9-2.6). The aphid honeydews did not prolong female longevity whereas Biogluc $^{\circledR} 50 \%$ significantly reduced longevity.

Similarly, treatment had a significant effect on the longevity of adult $F$. acarisuga females $(F=39.97$; d.f. $=9,190 ; P<0.0001)$ (Fig. 1B) whereas block ( $F=0.017$; d.f. $=1,189 ; P=0.918)$ and the interaction block*treatment $(F=0.634$; d.f. $=9,180 ; P=0.938)$ were not significant. Females lived longest when provided with Biogluc ${ }^{\circledast} 10 \%$, when compared to the water control, feeding on Biogluc ${ }^{\circledast}$ enhanced longevity by a factor of 4.7. The sucrose solutions had a less pronounced effect on the female longevity (increase by a factor of 2.0-3.2). The aphid honeydews did not prolong female longevity whereas Biogluc $^{\circledast} 50 \%$ significantly reduced longevity.

\subsection{Impact of sugars and honeydew on the number of oocytes of A. aphidimyza and $F$. acarisuga females}

Treatment had a significant effect on the number of oocytes of $A$. aphidimyza $(F=37.366$; d.f. 8, 192; $=P<0.0001)$ (Fig. 2A) whereas block $(F=0.054$; d.f. $=1,191 ; P=0.815)$ and the interaction block*treatment $(F=1.752$; d.f. $=8,183 ; P=0.081)$ were not significant. The highest number of oocytes was recorded for females provided with Biogluc ${ }^{\circledast}$ and sucrose independent of concentration. When compared to the water control, feeding on Biogluc ${ }^{\circledR}$ or sucrose raised the number of oocytes by a factor of 2.2-2.6. The M. persicae honeydew had a marginal, yet significant impact on the number of oocytes compared to the water control. The A. pisum honeydew treatment did not raise the number of oocytes.

Treatment had a significant effect on the number of oocytes of $F$. acarisuga ( $F=64.332$, d.f. $=8,169 ; \mathrm{P}<0.0001)$ (Fig. $2 \mathrm{~B}$ ) whereas block $(F=0.001 ;$ d.f. $=1,168 ; P=0.933)$ and the interaction block*treatment $(F=4.71$; d.f. $=8,160 ; P=0.715)$ were not significant. The highest number of oocytes was recorded for females provided with sucrose $50 \%$ and $25 \%$ followed by Biogluc ${ }^{\circledR} 10 \%$ and $25 \%$. When compared to the water control feeding on the above sugars raised the number of oocytes by a factor of 2.5, 2.2, 2.1 and 2.0, respectively. The number of oocytes was not different in females provided with $M$. persicae honeydew or water whereas the number of oocytes was reduced in the females provided with the honeydew of $A$. pisum.

\subsection{Impact of sugars and honeydew on the fecundity of A. aphidimyza and F. acarisuga females}

Treatment had a significant effect on the number of eggs laid by $A$. aphidimyza during $72 \mathrm{~h}(F=89.872$; d.f. $=8,110 ;=P<0.0001)$ (Fig. 3A) whereas block $(F=0.54$; d.f. $=1,109 ; P=0.71)$ and the interaction block*treatment $(F=1.446$; d.f. $=8,101 ; P=0.936)$ were not significant. The highest number of eggs laid during $72 \mathrm{~h}$ was registered for females provided with Biogluc ${ }^{\circledR} 50 \%$ followed by a second group of treatments comprising the rest of the Biogluc ${ }^{\circledR}$ as well as all the sucrose concentrations. When compared to the water control, feeding on the above sugars raised the number of eggs laid by a factor of 5.1, and between 3.0 and 3.7, for the second group of treatments. Honeydew from either M. persicae or A. pisum had a marginal, though significant impact on the number of eggs laid compared to the water control.

Treatment had a significant effect on the number of eggs laid by $F$. acarisuga during $72 \mathrm{~h}(F=31.895$; d.f. $=8,100 ;=P<0.0001)$ (Fig. 3B) whereas block $(F=0.48$; d.f. $=1,99 ; P=0.464)$ and the interaction block*treatment $(F=0.469$; d.f. $=8,91 ; P=0.844)$ were not significant. The highest number of eggs laid during $72 \mathrm{~h}$ was recorded for females provided with Biogluc ${ }^{\circledR} 10 \%$ followed by the treatments comprising the rest of the Biogluc ${ }^{\circledR}$ as well as all the sucrose concentrations. When compared to the water control, feeding on the above sugars raised the number of eggs laid during $72 \mathrm{~h}$ by a factor of 3.5 , while for the second group of treatments the increase was between 2.3 and 2.9. The fecundity of females provided with honeydew produced by either $M$. persicae or $A$. pisum did not differ from the water treatment.

The number of oocytes was positively correlated with the number of eggs laid during $72 \mathrm{~h}$ for both $A$. aphidimyza $(F=62.86$; $\mathrm{df}=1,7$; $P<0.0001 ; R^{2}=0.8855$ ) (Fig. $\left.4 \mathrm{~A}\right)$ and $F$. acarisuga $(F=36.93$; $\left.\mathrm{df}=1,7 ; P<0.0001 ; R^{2}=0.8179\right)$ (Fig. 4B).

\section{Discussion}

In the present study, we have shown that sugar type and concentration can have a profound impact on several fitness parameters of two life-history omnivores, the predatory gall midges A. aphidimyza and $F$. acarisuga. The results shed light on the nutritional ecology of these 

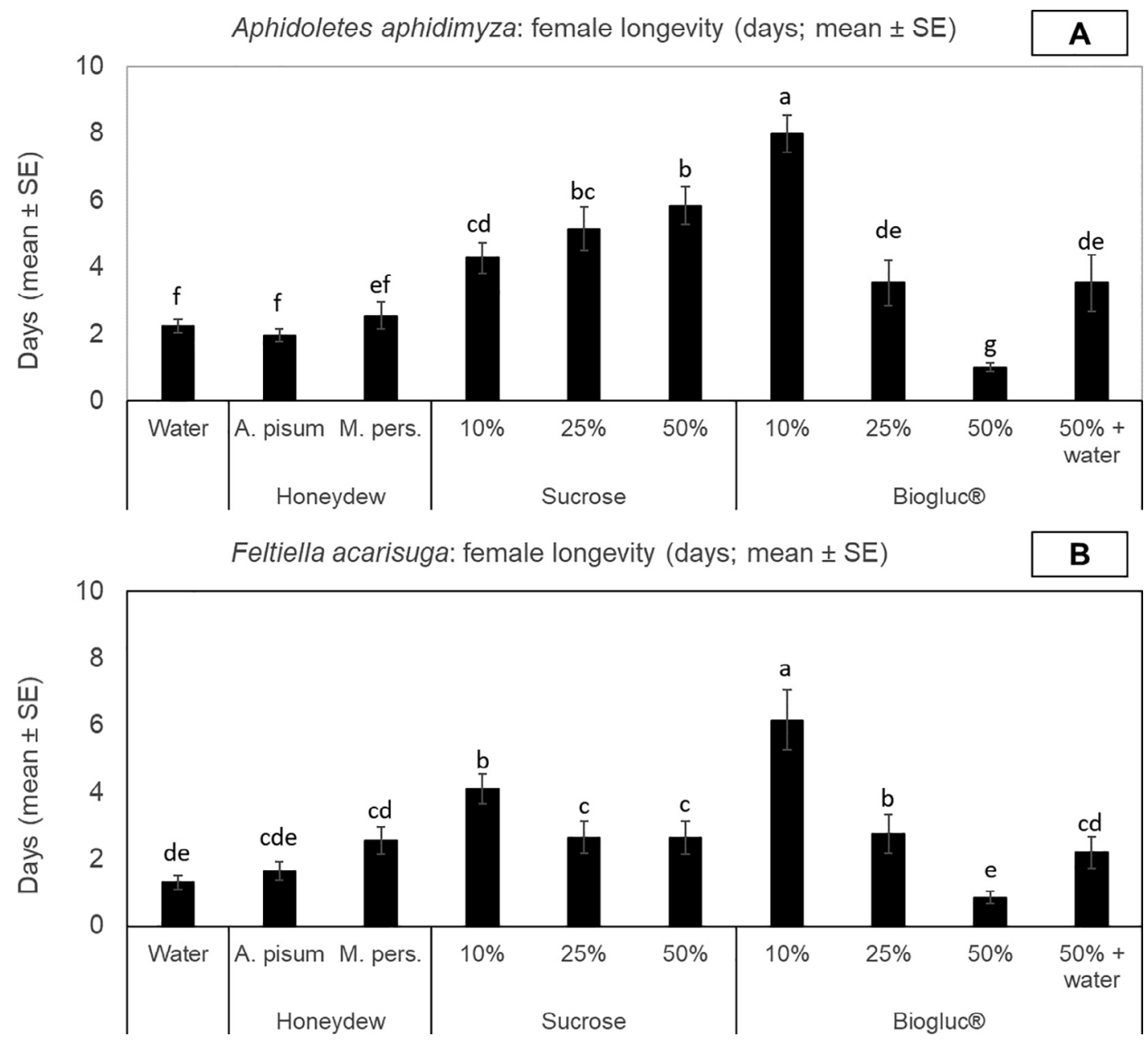

Fig. 1. Longevity (in days; mean \pm SE) of A) Aphidoletes aphidimyza and B) Feltiella acarisuga females when supplied with various sugar sources at different concentrations.

two species and have important practical implications for their effectiveness as pest controllers in applied biocontrol programs, for their mass rearing as well as for the experimental procedures employed by the biocontrol industry in Quality Control Assessments.

\subsection{Nutritional ecology}

Aphidoletes aphidimyza is an aphid predator. Thus, honeydew is directly associated with female recognition of presence of prey. It is thus expected that $A$. aphidimyza would be adapted to exploit this food source. In our study females supplied with aphid honeydew barely obtained any longevity or fecundity benefit from the tested honeydew compared to the water control. In the case of the spider-mite predator $F$. acarisuga, on the other hand, encounters with prey are not necessarily linked to access to sugars. Similar to A. aphidimyza, females of $F$. acarisuga obtained little or no benefit in terms of longevity and fecundity when supplied with aphid honeydew. In the case of females supplied with $A$. pisum honeydew, we even registered a negative impact on the number of oocytes for $F$. acarisuga compared to the water control. Previous studies reported a significant increase in the longevity of female $A$. aphidimyza supplied with $M$. persicae honeydew (from 3 days when provided with access to water only, to 16 days with access to honeydew) (Sell and Kuo-Sell, 1987). In this study, also lifetime fecundity was increased by more than $50 \%$ when honeydew was supplied. In another study, A. aphidimyza females supplied with artificial honeydew (containing variable percentages of fructose, glucose, sucrose, maltose, trehalose and melezitose) of three aphid species also showed considerably increased longevity and fecundity (Watanabe et al., 2014). Similarly, Brødsgaard et al. (1999) reported a significant increase in the fecundity of $F$. acarisuga when females had access to a continuous supply of $M$. persicae honeydew on full cucumber plants. The differences in experimental conditions between the current and previous studies might explain the divergence in results. Concretely, the fact that both the study by Sell and Kuo-Sell, (1987) and Brødsgaard et al. (1999) were performed with aphids reared on full plants might have had an impact on honeydew composition, availability and accessibility for females of $A$. aphidimyza and $F$. acarisuga. It is likely that in our experimental set-up honeydew accessibility (on leaf-disks or parafilm) was affected by evaporation and/or crystallization hampering feeding by the insects. In the study of Watanabe et al. (2014), the $A$. aphidimyza adults were kept in experimental units of bigger size $(10 \times 10 \times 20 \mathrm{~cm})$ and provided with artificial honeydew, lacking the secondary plant metabolites that may reduce honeydew nutritional quality for arthropod natural enemies (Tena et al., 2013b).

In any case, the results regarding the impact of aphid honeydew on the fitness of natural enemies (mainly parasitoids) are variable (Faria et al., 2008; Tena et al., 2013b; Wäckers et al., 2005). In studies where aphid honeydew proved as nutritionally poor for natural enemies this has been attributed to sugar composition (Wäckers, 2000), the presence of plant secondary metabolites (Tena et al., 2013b) and/or its high viscosity that hampers intake (Faria et al., 2008; Wäckers, 2000). It is important to highlight though that honeydew types can differ markedly in sugar concentration and chemical composition, which can impact the fitness of natural enemies (Faria et al., 2008; Ge et al., 2019; Tena et al., 

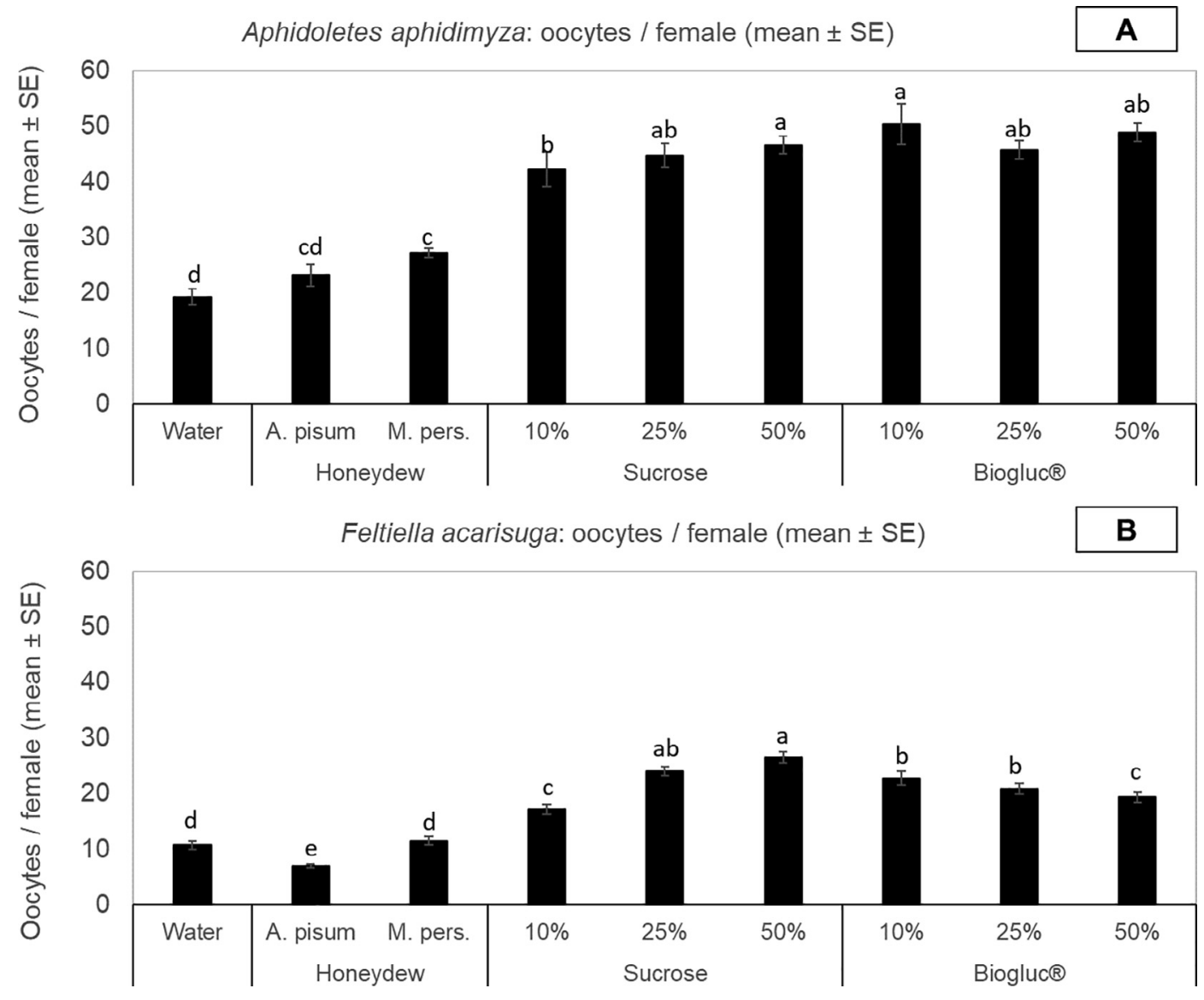

Fig. 2. Number of oocytes (mean \pm SE) for A) Aphidoletes aphidimyza and B) Feltiella acarisuga females when supplied with various sugar sources at different concentrations.

2013b). Thus, we cannot exclude the possibility that honeydew produced by other hemipteran species, such as mealybugs or soft scales, might have a different, positive impact on the fitness of $A$. aphidimyza and $F$. acarisuga as has been observed with other natural enemies (Tena et al., 2013b). Despite the lower nutritional quality and the potential risks of encountering ants that tend the insects that produce honeydew (Calabuig et al., 2015; Tena et al., 2013a), honeydew is the primary carbohydrate source available in time and space for arthropod natural enemies in agroecosystems (Tena et al., 2013c, 2016; Wäckers et al., 2008). Additionally, honeydew serves as an oviposition cue for female A. aphidimyza (Boulanger et al., 2018). Thus, despite our results, a role of hemipteran honeydew in the nutritional ecology of A. aphidimyza and $F$. acarisuga cannot be excluded.

Provisioning of sucrose or Biogluc ${ }^{\circledast}$, at the lowest of the concentrations tested $(10 \%)$, significantly increased longevity and fecundity in both species. Sucrose, as well as the main sugars dominating Biogluc $^{\circledR}$ (fructose, glucose and sucrose) are commonly found in floral and extrafloral nectar (Koptur, 2005; Wäckers, 2005). Our results suggest that $A$. aphidimyza and $F$. acarisuga could exploit this food source in the field provided access to nectar glands is not hampered by flower morphology. In a Y-tube olfactometer study, A. aphidimyza was highly attracted to the flowers of sweet alyssum, Lobularia maritima (L.) (Brassicaceae), however, adults were not able to access the nectaries inside the calix (Aparicio et al., 2018). There is no such information available in terms of nectar foraging and -feeding by $F$. acarisuga but the same benefits and limitations relating to floral nectar may apply for this species as well. Extrafloral nectar is also dominated by glucose, fructose and sucrose. Although sugar concentration in extrafloral nectar is higher than in floral nectar, it is lower than that in honeydew (Wäckers, 2005). The fact that the majority of extrafloral nectaries are fully exposed makes them an excellent and accessible food source for natural enemies and potentially for A. aphidimyza and F. acarisuga as well (Wäckers, 2005). To our knowledge, no information exists regarding feeding on extrafloral nectar by these species.

Increased sugar concentration marginally increased longevity in $A$. aphidimyza whereas the opposite effect was observed for $F$. acarisuga. The negative impact of increased Biogluc ${ }^{\circledast}$ concentration on longevity of both species was more pronounced. This might be attributed to the high sugar viscosity that might have hampered accessibility and as consequence the feeding frequency and duration (Heping et al., 2008); this is further supported by the fact that addition of water significantly increased the longevity of both species. Alternatively, the presence of oligosaccharides that have been shown to negatively impact the longevity of natural enemies (Wäckers, 2000) or preservatives in Biogluc ${ }^{\circledR}$ might have also played a role. Overall, the impact of sugar concentration on the longevity of natural enemies is variable. In previous studies with parasitoids, increased sugar concentration had positive (Williams et al., 2015) or negative impact on longevity (Siekmann et al., 2001). In practical terms, our results suggest that $F$. acarisuga obtains no fitness benefits when supplied with a viscous sugar source whereas $A$. aphidimyza, as a predator of aphids, might be better suited to exploit more viscous sugar sources such as dried-up honeydew. In any case, while natural enemies of honeydew-producing insects may be adapted to exploit honeydew as food source (Lenaerts et al., 2016) this is not universal (see also Wäckers et al., 2008).

It is important to highlight that, while both species tested survived longer on low concentration diets of Biogluc ${ }^{\oplus}$, oocyte production and eggs laid were higher on the $50 \%$ concentration diet. We suggest a potential trade-off between the reproductive output and the survival of A. aphidimyza and F. acarisuga when females had access to the $50 \%$ 

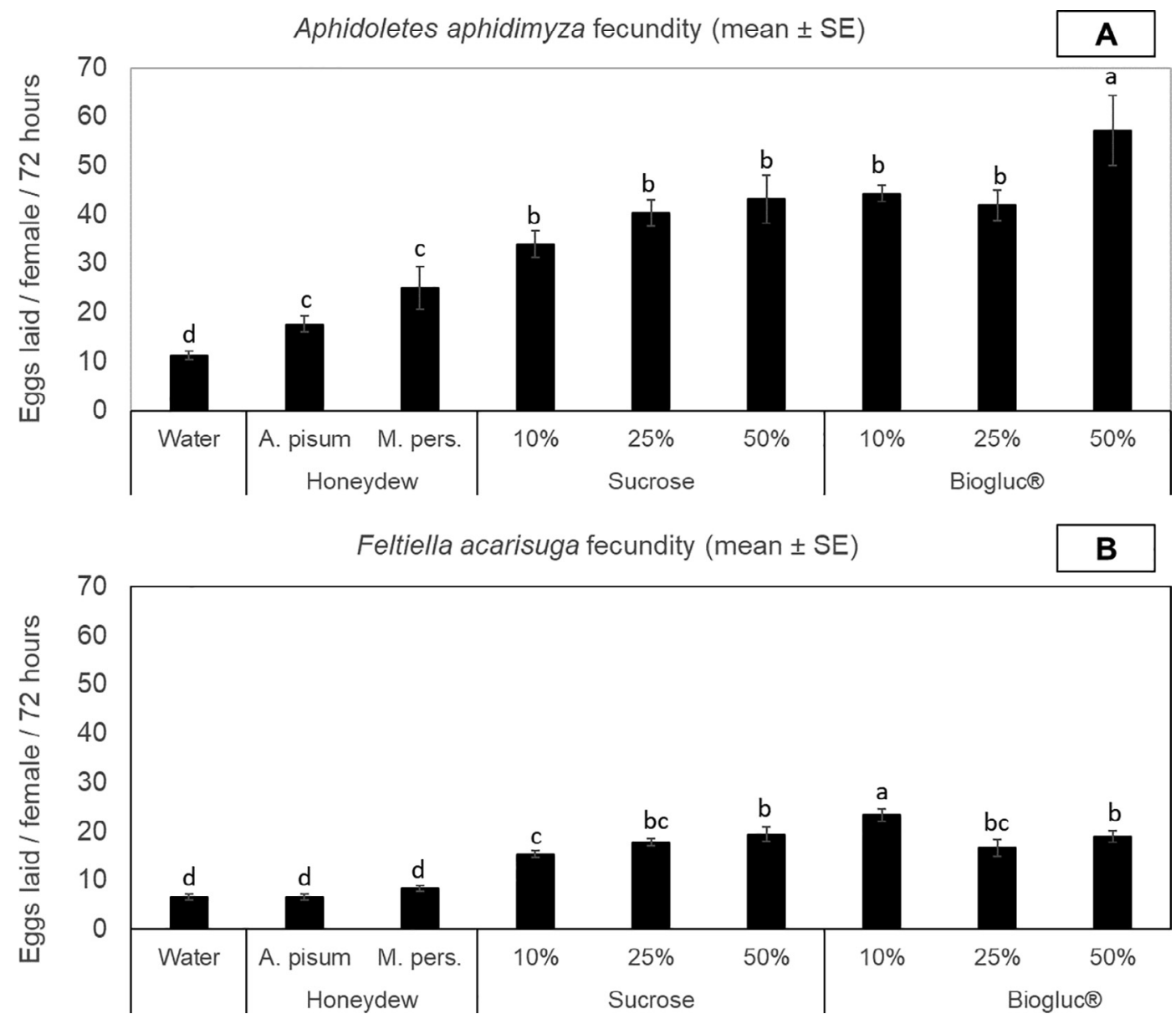

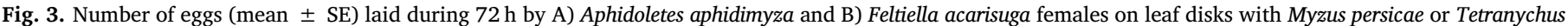
urticae, respectively, when supplied with various sugar sources at different concentrations.
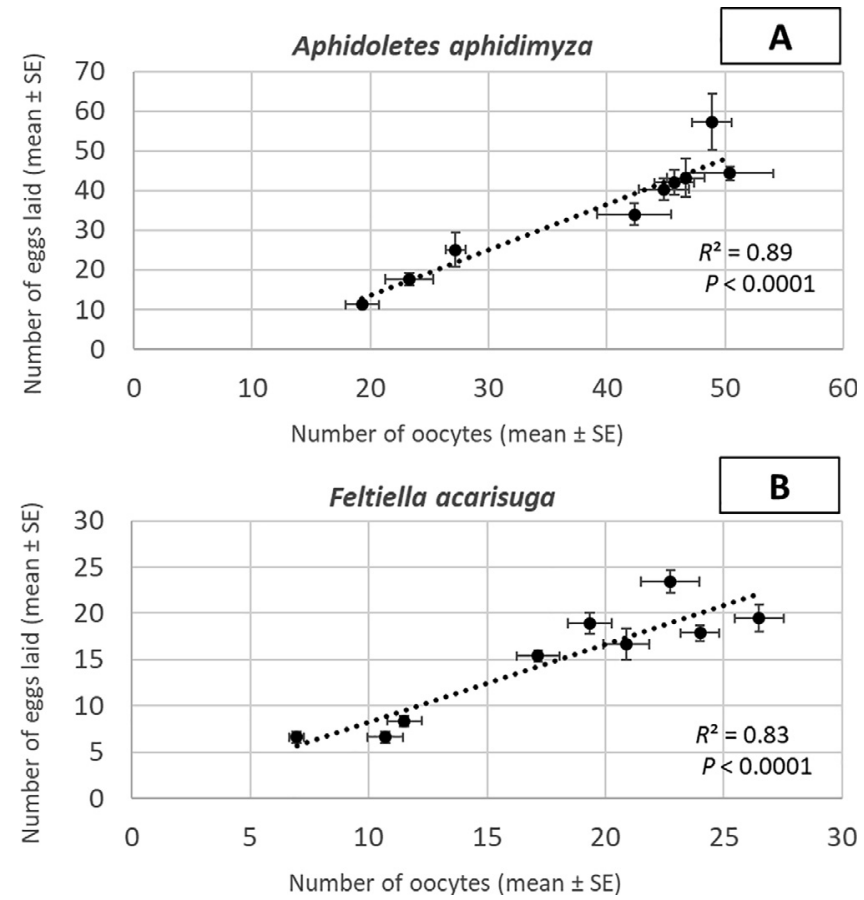

Fig. 4. Relationship between the number of oocytes (mean $\pm S E$ ) and the number of eggs laid (mean \pm SE) by A) Aphidoletes aphidimyza and B) Feltiella acarisuga females when supplied with various sugar sources at different concentrations.
Biogluc ${ }^{\circledR}$ concentration. In parasitoids, where the cost of reproduction is widely studied, a trade-off between the life span and reproductive output was determined for the first time in Asobara tabida Förster, (Hymenoptera: Braconidae) (Ellers and Van Alphen, 1997). In a later study, Ellers et al., (2000) showed that a linear (negative) relationship exists between egg production and mortality in the parasitoid A. tabida. It is possible that a competition between the maintenance of physiological function and egg production occurs in the species of our study as well.

The results from our honeydew treatments coupled with the fact that increased sucrose and Biogluc ${ }^{\circledR}$ concentrations had a negative impact on longevity makes us hypothesize that $F$. acarisuga might be better suited to exploit floral and/or extrafloral nectar. This might also apply for $A$. aphidimyza. In practice, it is likely that $F$. acarisuga and $A$. aphidimyza adults, apart from locating oviposition sites (prey), have to embark in separate, energetically costly foraging bouts to seek out suitable sugars. Certainly, field observations and studies employing analytical methods (see Calabuig et al., 2015; Steppuhn and Wäckers, 2004; Tena et al., 2013c) are needed to test which sugar sources are exploited by A. aphidimyza and F. acarisuga in natural and agricultural ecosystems.

\subsection{Practical implications for biological pest control}

In applied biocontrol programs, A. aphidimyza (Boulanger et al., 2018) and F. acarisuga are supplied as cocoons (pupae) to growers; adults emerge a few days afterwards and are expected to disperse into the crop and to locate aphids and spider mites, respectively, to lay their eggs. Typically, no sugars are supplied to the recently emerged adults. 
Our results show, that in agricultural cropping systems lacking nectar sources this may seriously compromise the longevity and fecundity of $A$. aphidimyza and $F$. acarisuga. Adult females of both species lived no longer than two days in the laboratory when provided with water only and showed the lowest egg load and oviposition rates. In the field, where the adults have to search for hosts over long distances, the absence of sugar feeding is expected to have an even more pronounced impact. Consequently, provisioning of sugars in the field will be of high importance for A. aphidimyza and F. acarisuga to realize their full biocontrol potential. Sugar sprays, notably Biogluc at $10 \%$ concentration, has been shown to enhance the abundance of resident populations of phytoseiid predatory mites in citrus (Beltrà et al., 2017). Similarly, spraying a $4 \%$ sugar solution containing a mixture of sucrose, glucose and fructose increased parasitoid abundance and resulted in higher levels of parasitism in the field (Tena et al., 2015). Based on our results and previous experience (Beltrà et al., 2017; Pekas and Wäckers, 2017), Biogluc $^{\circledast}$ at $10 \%$ concentration seems to be a good candidate for use in conservation and augmentative biological control programs. It is important to note that pests might also benefit from sugar feeding. Our previous experience with Biogluc ${ }^{\circledR}$ comes mainly from citrus where we did not observe any pest outbreaks nor any sooty mold developing on the leaves after sugar provisioning (Beltrà et al., 2017). The conditions and pest incidence though vary considerably among crops. Therefore, the selectivity of the sugars to be used for enhancing the establishment and performance of natural enemies should be tested before application (Winkler, 2005).

\subsection{Implications for the mass rearing}

Our results can also have practical implications for the mass rearing of the two predators. Provisioning of sucrose or Biogluc ${ }^{\circledR}$ considerably enhanced the lifespan and fecundity of both A. aphidimyza and $F$. acarisuga. Thus, provisioning of these sugars in the mass rearing is expected to increase the yield and consequently the cost-efficiency of the system, something highly desirable for the biocontrol industry. Given that Biogluc ${ }^{\circledast}$ is of known and stable composition it seems to be a suitable sugar source to be provided in the mass rearing. Based on our results, we recommend Biogluc ${ }^{\circledR}$ at $10 \%$ concentration to be offered in the oviposition cages of $A$. aphidimyza and $F$. acarisuga.

\subsection{Quality control}

Currently, the quality control guidelines for assessing the fecundity of $A$. aphidimyza include oviposition tests over $72 \mathrm{~h}$ (after adult emergence) on leaf disks infested with aphids. Hence, it is necessary to grow plants and maintain aphid populations in order to perform these tests. Our results show that there is a significant correlation between the number of oocytes and the number of eggs laid, i.e. that the former might be used as a reliable proxy for the latter. In practice, this would considerably simplify the quality control procedures for A. aphidimyza and we propose that the same method could be applied for evaluating the fecundity of $F$. acarisuga as well.

\section{Conclusion}

Overall, we have shown that sugar type and concentration can have a profound impact on the fitness of two commercially available lifehistory omnivores used in biological control. Both A. aphidimyza and $F$. acarisuga females obtain barely any fitness benefit when supplied with aphid honeydew. In contrast, longevity, egg-load and fecundity over $72 \mathrm{~h}$ were considerably increased for females supplied with sucrose or particularly Biogluc ${ }^{\circledast}$ (the latter at $10 \%$ concentration). Increased sugar concentration was not accompanied by an increase in fitness. Given its known and stable composition we recommend Biogluc ${ }^{\circledR}$ at $10 \%$ concentration to be supplied to the A. aphidimyza and $F$. acarisuga adults before they are released in the field and in the mass rearing.
Examination of the oocytes instead of the number of eggs laid over $72 \mathrm{~h}$ could considerably simplify the quality control procedures for $A$. aphidimyza and $F$. acarisuga.

\section{CRediT authorship contribution statement}

Stefano Fratoni: Investigation, Methodology, Validation, Data curation, Writing - original draft. Marcus V.A. Duarte: Conceptualization, Methodology, Supervision, Writing - original draft, Writing - review \& editing. Dominiek Vangansbeke: Conceptualization, Methodology, Supervision, Writing - original draft, Writing - review \& editing. Felix L. Wäckers: Conceptualization, Writing - review \& editing. Marcel Dicke: Conceptualization, Supervision, Writing - review \& editing. Apostolos Pekas: Conceptualization, Methodology, Supervision, Data curation, Formal analysis, Writing - original draft, Writing - review \& editing, Project administration.

\section{Acknowledgements}

Lien de Smedt and Kim Ost for providing help with the trials. Stefano Fratoni was recipient of an Erasmus Plus fellowship.

\section{Appendix A. Supplementary data}

Supplementary data to this article can be found online at https:// doi.org/10.1016/j.biocontrol.2019.104098.

\section{References}

Aparicio, Y., Gabarra, R., Arnó, J., 2018. Attraction of Aphidius ervi (Hymenoptera: Braconidae) and Aphidoletes aphidimyza (Diptera: Cecidomyiidae) to sweet alyssum and assessment of plant resources effects on their fitness. J. Econ. Entomol. 111, 533-541. https://doi.org/10.1093/jee/tox365.

Beltrà, A., Calabuig, A., Navarro-Campos, C., José Ramírez-Soria, M., Soto, A., GarciaMarí, F., Wäckers, F.L., Pekas, A., 2017. Provisioning of food supplements enhances the conservation of phytoseiid mites in citrus. Biol. Control 115, 18-22. https://doi. org/10.1016/j.biocontrol.2017.09.007.

Boulanger, F.-X., Jandricic, S., Bolckmans, K., Wäckers, F.L., Pekas, A., 2018. Optimizing aphid biocontrol with the predator Aphidoletes aphidimyza, based on biology and ecology. Pest Manage. Sci. https://doi.org/10.1002/ps.5270.

Brødsgaard, H., Jacobsen, S., Enkegaard, A., 1999. Life table characteristics of the predatory gall midge Feltiella acarisuga. IOBC Bull. Integr. Control Greenhouses 22, 17-20.

Calabuig, A., Tena, A., Wäckers, F.L., Fernández-Arrojo, L., Plou, F.J., Garcia-Marí, F., Pekas, A., 2015. Ants impact the energy reserves of natural enemies through the shared honeydew exploitation. Ecol. Entomol. 40, 687-695. https://doi.org/10. 1111/een.12237.

Chazeau, J., 1985. Predaceous insects. In: Helle, W., Sabelis, M.W. (Eds.), World Crop Pests, Vol. 1B. Spider Mites: Their Biology, Natural Enemies and Control. Elsevier, Amsterdam, pp. 211-246.

Crawley, M.J., 2007. The R Book. John Wiley \& Sons Ltd, Chichester, West Sussex, England.

Duarte, M.V.A., Venzon, M., Bittencourt, M.C.D.S., Rodríguez-Cruz, F.A., Pallini, A., Janssen, A., 2015. Alternative food promotes broad mite control on chilli pepper plants. BioControl 60, 817-825. https://doi.org/10.1007/s10526-015-9688-x.

Ellers, J., Driessen, G., Sevenster, J.G., 2000. The shape of the trade-off function between egg production and life span in the parasitoid Asobara tabida. Netherlands J. Zool. 50, 29-36.

Ellers, J., Van Alphen, J.J.M., 1997. Life history evolution in Asobara tabida: plasticity in allocation of fat reserves to survival and reproduction. J. Evol. Biol. 10, 771-785. https://doi.org/10.1007/s000360050053.

Faria, C.A., Wäckers, F.L., Turlings, T.C.J., 2008. The nutritional value of aphid honeydew for non-aphid parasitoids. Basic Appl. Ecol. 9, 286-297. https://doi.org/10. 1016/j.baae.2007.02.001.

Ge, Y., Liu, P., Zhang, L., Snyder, W.E., Smith, O.M., Shi, W., 2019. A sticky situation: honeydew of the pear psylla disrupts feeding by its predator Orius sauteri. Pest Manage. Sci. https://doi.org/10.1002/ps.5498.

Heping, W., Ling, M., Baoping, L., 2008. Effects of feeding frequency and sugar concentrations on lifetime reproductive success of Meteorus pulchricornis (Hymenoptera: Braconidae). Biol. Control 45, 353-359. https://doi.org/10.1016/J.BIOCONTROL. 2008.01.017.

Koptur, S., 2005. Nectar as fuel for plant protectors. In: Wäckers, F.L., van Rijn, P.C.J., Bruin, J. (Eds.), Plant-Provided Food for Carnivorous Insects: A Protective Mutualism and Its Applications. Cambridge University Press, pp. 75-108.

Lenaerts, M., Abid, L., Paulussen, C., Goelen, T., Wäckers, F., Jacquemyn, H., Lievens, B., 
2016. Adult parasitoids of honeydew-producing insects prefer honeydew sugars to cover their energetic needs. J. Chem. Ecol. 42, 1028-1036. https://doi.org/10.1007/ s10886-016-0764-1.

Pekas, A., Wäckers, F.L., 2017. Multiple resource supplements synergistically enhance predatory mite populations. Oecologia 184. https://doi.org/10.1007/s00442-017. 3877-5.

Sell, P., Kuo-Sell, H.-L., 1987. Leistungsfähigkeit der aphidophagen Gallmücke Aphidoletes aphidimyza (Rond.)(Diptera, Cecidomyiidae) in Abhängigkeit von verschiedenen Einflu \s sfaktoren. J. Appl. Entomol. 103, 434-447.

Siekmann, G., Tenhumberg, B., Keller, M.A., 2001. Feeding and survival in parasitic wasps: sugar concentration and timing matter. Oikos 95, 425-430. https://doi.org/ 10.1034/j.1600-0706.2001.950307.x.

Steppuhn, A., Wäckers, F.L., 2004. HPLC sugar analysis reveals the nutritional state and the feeding history of parasitoids. Funct. Ecol. 18, 812-819. https://doi.org/10. 1111/j.0269-8463.2004.00920.x.

Takasu, K., Lewis, W.J., 1995. Importance of adult food sources to host searching of the larval parasitoid Microplitis croceipes. Biol. Control 5, 25-30. https://doi.org/10. 1006/BCON.1995.1003.

Tena, Hoddle, C.D., Hoddle, M.S., 2013a. Competition between honeydew producers in an ant-hemipteran interaction may enhance biological control of an invasive pest. Bull. Entomol. Res. 103, 714-723. https://doi.org/10.1017/S000748531300045X.

Tena, Llácer, E., Urbaneja, A., 2013b. Biological control of a non-honeydew producer mediated by a distinct hierarchy of honeydew quality. Biol. Control 67, 117-122. https://doi.org/10.1016/j.biocontrol.2013.07.018.

Tena, Pekas, A., Wäckers, F.L., Urbaneja, A., 2013c. Energy reserves of parasitoids depend on honeydew from non-hosts. Ecol. Entomol. 38, 278-289. https://doi.org/10.1111/ een.12018.

Tena, A., Pekas, A., Cano, D., Wäckers, F.L., Urbaneja, A., 2015. Sugar provisioning maximizes the biocontrol service of parasitoids. J. Appl. Ecol. 52, 795-804. https:// doi.org/10.1111/1365-2664.12426.

Tena, A., Wäckers, F.L., Heimpel, G.E., Urbaneja, A., Pekas, A., 2016. Parasitoid nutritional ecology in a community context: the importance of honeydew and implications for biological control. Curr. Opin. Insect Sci. https://doi.org/10.1016/j.cois.2016.02. 008.

van Lenteren, J., Hale, A., Klapwijk, J., Van Schelt, J., Steinberg, S., 2003. Guidelines for quality control of commercially produced natural enemies. In: van Lenteren, J. (Ed.), Quality Control and Production of Biological Control Agents: Theory and Testing Procedures. CABI Publishing, Wallingford, pp. 265-303.

van Lenteren, J.C., Bolckmans, K., Köhl, J., Ravensberg, W.J., Urbaneja, A., 2017. Biological control using invertebrates and microorganisms: plenty of new opportunities. BioControl 1-21. https://doi.org/10.1007/s10526-017-9801-4.

Vangansbeke, D., Nguyen, D.T., Audenaert, J., Gobin, B., Tirry, L., Clercq, P. De, 2016a. Establishment of Amblyseius swirskii in greenhouse crops using food supplements. Syst. Appl. Acarol. 21, 1174-1184. https://doi.org/10.11158/saa.21.9.2.

Vangansbeke, D., Nguyen, D.T., Audenaert, J., Verhoeven, R., Gobin, B., Tirry, L., De Clercq, P., 2016b. Supplemental food for Amblyseius swirskii in the control of thrips: feeding friend or foe? Pest Manage. Sci. 72, 466-473. https://doi.org/10.1002/ps. 4000 .

Wäckers, F.L., 2000. Do oligosaccharides reduce the suitability of honeydew for predators and parasitoids? A further facet to the function of insect-synthesized honeydew sugars. Oikos 90, 197-201. https://doi.org/10.1034/j.1600-0706.2000.900124.x.

Wäckers, F.L., 2005. Suitability of (extra-) floral nectar, pollen, and honeydew as insect food sources. In: Wäckers, F.L., Van Rijn, P.C.J., Bruin, J. (Eds.), Plant-Provided Food for Carnivorous Insects A Protective Mutualism and Its Applications. Cambridge University Press, Cambridge, UK, pp. 17-74. https://doi.org/10.1017/ CBO9780511542220.003.

Wäckers, F.L., van Rijn, P.C.J., Bruin, J., 2005. Plant-Provided Food for Carnivorous Insects, A Protective Mutualism and its Applications. Cambridge University Press, Cambridge. https://doi.org/10.1017/cbo9780511542220.

Wäckers, F.L., van Rijn, P.C.J., Heimpel, G.E., 2008. Honeydew as a food source for natural enemies: making the best of a bad meal? Biol. Control 45, 176-184. https:// doi.org/10.1016/j.biocontrol.2008.01.007.

Wäckers, F.L., Alberola, J.S., Garcia-Marí, F., Pekas, A., 2017. Attract and distract: manipulation of a food-mediated protective mutualism enhances natural pest control. Agric. Ecosyst. Environ. 246. https://doi.org/10.1016/j.agee.2017.05.037.

Watanabe, H., Katayama, N., Yano, E., Sugiyama, R., Nishikawa, S., Endou, T., Watanabe, K., Takabayashi, J., Ozawa, R., 2014. Effects of aphid honeydew sugars on the longevity and fecundity of the aphidophagous gall midge Aphidoletes aphidimyza. Biol. Control 78, 55-60. https://doi.org/10.1016/j.biocontrol.2014.07.007.

Williams, L., Deschodt, P., Pointurier, O., Wyckhuys, K.A.G., 2015. Sugar concentration and timing of feeding affect feeding characteristics and survival of a parasitic wasp. J. Insect Physiol. 79, 10-18. https://doi.org/10.1016/j.jinsphys.2015.05.004.

Winkler, K., 2005. Assessing the Risks and Benefits of Flowering Field Edges: Strategic Use of Nectar Sources to Boost Biological Control. PhD Thesis. Wageningen University, The Netherlands.

Winkler, K., Wäckers, F., Bukovinszkine-Kiss, G., Van Lenteren, J., 2006. Sugar resources are vital for Diadegma semiclausum fecundity under field conditions. Basic Appl. Ecol. 7, 133-140. https://doi.org/10.1016/j.baae.2005.06.001.

Winston, P.W., Bates, D.H., 1960. Saturated solutions for the control of humidity in biological research. Ecology 41, 232-237. https://doi.org/10.2307/1931961. 